\title{
Nonsense mutations inhibit splicing of MVM RNA in cis when they interrupt the reading frame of either exon of the final spliced product
}

\author{
Lisa Kay Naeger, Robert V. Schoborg, ${ }^{1}$ Qihong Zhao, Gregory E. Tullis, and David J. Pintel ${ }^{2}$ \\ Department of Molecular Microbiology and Immunology, University of Missouri-Columbia, School of Medicine, Columbia, \\ Missouri 65212 USA
}

mRNAs R1 and R2 of the autonomous parvovirus minute virus of mice (MVM), which encode the viral nonstructural proteins NS1 and NS2, respectively, are processed in an ordered splicing pathway in which R2 is generated from mature spliced R1. Introduction of translation termination signals into these genes alters the processing of these RNAs; there is a significant (up to fourfold) increase in the accumulated steady-state levels of $R 1$ relative to $R 2$, when compared with wild-type levels, although the total accumulated levels of R1 plus $R 2$ remain the same. The increase in accumulated $R 1$ relative to $R 2$ in mutant infected or transfected murine cells is independent of RNA stability and transport and decreases, in a polar manner, with the distance of the inserted termination signal from the shared initiation codon for NS1 and NS2 at nucleotide 260 . The increased ratio of $R 1$ to $R 2$ is a consequence of the artificially introduced translation termination signals acting in cis rather than in the absence of a functional viral gene product. These mutations have an effect when they interrupt previously open reading frames in either exon of the spliced product R2. Nonsense mutations that are located in the second exon of $R 2$ inhibit splicing of $R 1$ to $R 2$ only when they interrupt an open reading frame (ORF) that has the potential, after normal splicing, to be joined in-frame with the initiating AUG. These results suggest that nonsense mutations inhibit splicing of R1 to R2 by influencing the mechanism by which exons are defined in murine cells.

[Key Words: Nonsense mutations; splicing; exon definition; parvovirus]

Received February 3, 1992; revised version accepted March 24, 1992.

It has been known for some time that in various prokaryotic systems and in yeast, premature translation termination of certain mRNAs can result in their destabilization (Adhya and Gottesman 1978; Losson and Lacroute 1979; Kennell 1986; Nilsson et al. 1987; Brown 1989; Peltz et al. 1990). Mutations that terminate translation prematurely in higher eukaryotes have also been shown in some cases to act in cis to affect reduced cytoplasmic mRNA levels. Although the precise mechanism of this effect is still unclear, primary alterations in RNA synthesis and stability (Maquat et al. 1981; Graves et al. 1987; Arrigo and Beemon 1988; Peltz et al. 1990; Barker and Beemon 1991) and RNA processing and transport (Humphries et al. 1984; Takeshita et al. 1984; Baumann et al. 1985; Baserga and Benz 1988; Daar and Maquat 1988; Urlaub et al. 1989; Cheng et al. 1990; Peltz et al. 1990) have been proposed. Here, we report that introduction of translation termination signals into the open

\footnotetext{
${ }^{1}$ Present address: Division of Comparative Medicine, Johns Hopkins University School of Medicine, Baltimore, Maryland 21205 USA.

${ }^{2}$ Corresponding author.
}

reading frames (ORFs) encoding the nonstructural genes NS1 and NS2 of the autonomous parvovirus minute virus of mice (MVM) act in cis to alter the processing of viral RNA in the nucleus of murine cells.

MVM, a member of the autonomously replicating subgroup of parvoviruses (for review, see Cotmore and Tattersall 1987; Berns 1990), is organized into two overlapping transcription units that produce three major transcript classes, all of which terminate near the right-hand end of the 5-kb viral genome (Pintel et al. 1983; Astell et al. 1986; Clemens and Pintel 1987) (Fig. 1A). Transcripts $\mathrm{R} 1(4.8 \mathrm{~kb})$ and $\mathrm{R} 2(3.3 \mathrm{~kb})$ are generated from a promoter (P4) at viral map unit 4 (Pintel et al. 1983) and encode the viral nonstructural proteins NS1 $(83 \mathrm{kD})$ and NS2 $(24$ $\mathrm{kD}$ ), respectively (Cotmore and Tattersall 1986). The R3 $(3.0 \mathrm{~kb})$ transcripts, generated from a promoter (P38) at map unit 38 , encode the overlapping viral capsid proteins VP1 and VP2 from alternatively spliced mRNAs, using the ORF in the right half of the genome (Jongeneel 1986; Labieniec-Pintel and Pintel 1986). Polyadenylation of MVM RNAs precedes splicing /Clemens and Pintel 1988). Three splicing patterns are used to excise a small 
intron at map units $44-46$, which is common to all three transcript classes, resulting in nine different spliced MVM mRNA species (Jongeneel et al. 1986; Morgan and Ward 1986; Clemens et al. 1990; Cotmore and Tattersall 1990). The R2 transcripts are additionally spliced between map units 10 and 39 (Pintel et al. 1983; Cotmore and Tattersall 1986; Jongeneel et al. 1986; Clemens et al. 1990).

There is a regulated, temporal phasing of the accumulation of MVM RNA and protein: The products of the P4 promoter (the nonstructural genes) are produced before the products of the P38 promoter (the capsid genes) (Clemens and Pintel 1988; Cotmore and Tattersall 1990; Schoborg and Pintel 1991). Later in infection, the products of the P38 promoter become predominant (Pintel et al. 1983; Clemens and Pintel 1988; Schoborg and Pintel 1991). The steady-state levels of the nonstructural proteins, which are of critical importance for efficient viral replication, are also controlled at the level of RNA processing (Schoborg and Pintel 1991). Analysis of the accumulation of MVM RNA in highly synchronized cells has shown that R2 accumulates faster and to a greater amount than R1 in both total and cytoplasmic RNA throughout infection, even although they are generated from the same promoter and have similar stabilities (Schoborg and Pintel 1991). Detailed characterization of the accumulation of the various spliced and unspliced forms of MVM RNA has suggested a preferred (but not obligatory) order of splicing in which the R2 transcripts are generated from polyadenylated, spliced Rl RNAs (Clemens and Pintel 1988; Schoborg 1991; Schoborg and Pintel 1991; R.V. Schoborg, G. Tullis, Q. Zhao, and D. Pintel, unpubl.; R.V. Schoborg, Q. Zhao, and D.J. Pintel, in prep.) (Fig. 1B). Consistent with this model, cDNA constructs in which the small intron at map units 44-46 has been removed are impaired severely in further splicing of the large intron between map units 10 and 39 to form R2 (Schoborg 1991; R.V. Schoborg, G. Tullis, Q. Zhao, and D. Pintel, unpubl.; R.V. Schoborg, Q. Zhao, and D.J. Pintel, in prep.). The ratio of accumulated R1 to $\mathrm{R} 2$ is dependent on the percentage of $\mathrm{R} 1$ that undergoes subsequent removal of the large intron/Clemens and Pintel 1988; Schoborg 1991; Schoborg and Pintel 1991; R.V. Schoborg, G. Tullis, Q. Zhao, and D. Pintel, unpubl.; R.V. Schoborg, Q. Zhao, and D.J. Pintel, in prep.). The regulation of this event is critical in determining the steady-state levels of NS1 and NS2 (Schoborg and Pintel 1991) and, therefore, in determining the optimal balance between the essential roles of these proteins in viral replication and cytotoxicity (Cotmore and Tattersall 1987; Berns 1990). Regulation of the splicing of R1 to form R2 is mediated, at least in part, in cis by a nonconsensus donor (AA/GCAAG) at nucleotide 514 for the R2 large intron. When this donor is changed to consensus (AG/ GTAAG), the majority of $\mathrm{R} 1$ is processed further to $\mathrm{R} 2$ (Schoborg 1991; R.V. Schoborg, G. Tullis, Q. Zhao, and D. Pintel, unpubl.; R.V. Schoborg, Q. Zhao, and D.J. Pintel, in prep.).

To determine whether any MVM gene products were involved in the regulation of the processing of $\mathrm{R} 1$ to $\mathrm{R} 2$, we examined a set of mutants in which translation termination signals were introduced into the coding regions of the nonstructural genes of MVM. We noticed that for several of these mutants the ratio of accumulated Rl relative to $\mathrm{R} 2$ was increased significantly compared with wild type, although the total accumulated levels of R1 plus R2 remained the same. The increase in accumulated $R 1$ relative to $R 2$, in mutant infected or transfected murine cells, is independent of RNA stability and transport, and the magnitude of the increase is correlated in a polar manner with the distance of the inserted termination codon from the shared initiation codon for NS1 and NS2 at nucleotide 260 . The defect in processing of $\mathrm{R} 1$ to $\mathrm{R} 2$ is not complemented in trans by the viral nonstructural gene products. Mutational analysis has demonstrated that the increase in accumulated $\mathrm{R} 1$ relative to $\mathrm{R} 2$ is a consequence of cis-acting signals rather than the absence of a functional viral gene product. These cis-acting termination signals produce their effect when they interrupt previously open reading frames in either exon of R2. Nonsense mutations that are localized in the second exon of R2 inhibit splicing of R1 to R2 only when they interrupt an ORF that has the potential to be joined inframe to the initiating AUG after normal splicing. These results suggest that nonsense mutations inhibit the splicing of Rl by influencing the mechanism by which exons are defined in murine cells. Because the processing of MVM RNAs is relatively simple and well defined, it provides a good model in which to study this association.

\section{Results}

Artificially introduced ochre termination codons in the nonstructural genes of MVM result in greater than wild-type accumulated ratios of $R 1$ relative to $R 2$

To assess the possible role of the MVM nonstructural proteins during the regulated accumulation of $\mathrm{R} 1$ and R2, a 16-nucleotide palindromic linker, containing ochre termination signals in all three reading frames, was inserted into pLLP- $\Delta H$ at nucleotide 385 . This insertion terminates both nonstructural genes NS1 and NS2, which share ORF 3 in this region (Fig. 1A). When the mutant plasmid (p385UTT) was transfected into murine A9 fibroblasts, very little P38-generated R3 RNA was detected, as expected (Fig. 2, lane 8), because the P38 promoter is dependent on NS1 for activation (Rhode 1985; Doerig et al. 1988; Schoborg and Pintel 1991). In addition, a significantly higher ratio of accumulated Rl to $\mathrm{R} 2$ was seen compared with parallel transfections of wild-type plasmids (Fig. 2A, lanes 2,8; Table 1). Extensive characterization of the rates and levels of accumulation of wild-type MVM RNAs during highly synchronous infection of murine A9 cells had demonstrated previously that MVM R2 accumulates faster and to a greater amount than Rl in both total and cytoplasmic RNA fractions throughout infection (Schoborg and Pintel 1991). In contrast, p385UTT, in which both nonstructural proteins were prematurely terminated, generated approxi- 

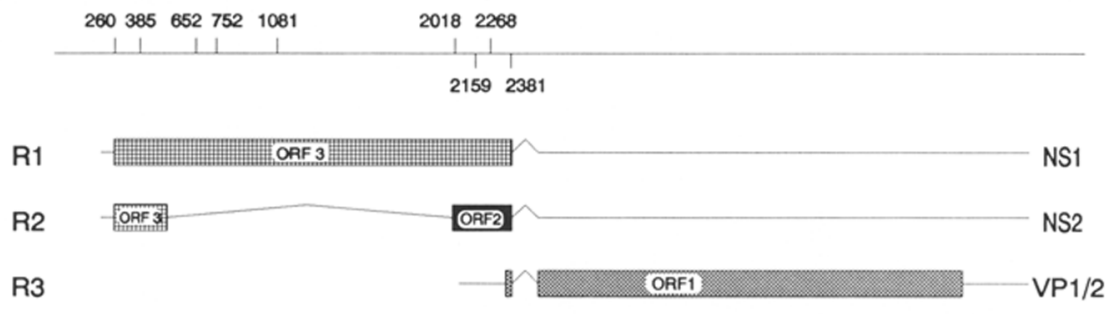

Figure 1. (A) Genetic map of MVM. The three major MVM transcript classes and protein-encoding ORFs are shown. Locations of most of the mutants used in this study are diagramed on the top line. The bottom line shows nucleotide locations and the three probes used for RNase protection assays as described in Materials and methods. There are no significant ORFs in MVM other than those indicated. $(B)$ Splicing pathway of the P4-generated RNAs Rl and R2. The nonconsensus splice donor site for $\mathrm{R} 2$ at nucleotide 514 is indicated (ncD).

mately fourfold more viral R1 than R2 after transfection. In this and all subsequent analyses, all spliced and unspliced forms of R1 and R2 have been included in the quantitation.

Nonsense mutations were also introduced exclusively into the NS1 ORF at nucleotides 652 [p652(T4), p652UTT(T4), p652UTT(MB)], 762 (p762UTT), and 1081 (p1081UTT) (Fig. 1A). These mutant plasmids generated essentially wild-type ratios of accumulated $\mathrm{R} 1$ relative to R2 (Fig. 2A, lanes 3-7; Table 1), although transcription from P38 was abolished, as expected.

We then examined the relative RNA levels generated by an MVM mutant that exclusively affects NS2 (NS22018) (Naeger et al. 1990). In this mutant, NS2 is truncated as a consequence of an ochre termination signal that was introduced by site-directed mutagenesis into the unique second exon of NS2 in ORF 2 at nucleotide 2018 (Fig. 1A) (Naeger et al. 1990). Plasmids containing this mutant generated significantly increased levels of accumulated $\mathrm{R} 1$ relative to $\mathrm{R} 2$ when compared with wild type after transfection into A9 cells (Fig. 2, lane 9; Table 1), although the increase was not as great as that seen for p385UTT.

Virus containing nonsense mutations in NS2 display an increased ratio of accumulated $R 1$ to $R 2$ throughout synchronous infection, which was exhibited in a polar manner

We have previously characterized a series of MVM NS2 mutants, including NS2-2018, in which ochre termination signals have been introduced at several positions in
ORF 2 in the second exon of R2 (Naeger et al. 1990). These mutants, in which NS1 is unaffected, are defective for single-strand progeny DNA accumulation and efficient virus production on the normal tissue culture host, murine A9 cells (Fig. 3). They can, however, be propagated on a number of other nonmurine cell types (Naeger et al. 1990), permitting the generation of NS2 mutant virus stocks. NS2-2018 virus generated the same increased levels of $\mathrm{R} 1$ relative to $\mathrm{R} 2$ throughout infection of highly synchronous murine A9 cells, as seen after transfection of the parent mutant plasmid (Fig. 3). These results confirm that the increased accumulated ratio of $\mathrm{R} 1$ to $\mathrm{R} 2$ described above for mutant plasmids is not unique to the transfection process. In addition, examination of the RNAs generated from four NS2 mutants that terminate at different points in the second exon of NS2 (NS2-2018, NS2-2159, NS2-2268, NS2-2381; see Fig. 1A) demonstrated that the increased $R 1$ to $R 2$ ratios detected are related, in a polar fashion, to the distance of the mutation from the initiating AUG for NS1 and NS2 at nucleotide 260 (and from the $5^{\prime}$ end of R1 and R2) (Fig. 4). The relative increase of accumulated ratios of $\mathrm{R} 1$ to R2, compared with wild type, seen during NS2-2018 infection, was greater than that for NS2-2159, whereas mutants NS2-2268 and NS2-2381 exhibited wild-type accumulated ratios of R1 to R2 (Fig. 4).

Although the accumulated levels of $\mathrm{R} 1$ relative to $\mathrm{R} 2$ after infection or transfection of NS2-2018 was significantly increased compared with wild type, the accumulated levels of total P4-generated RNA (R1 plus R2) remained the same, compared with P38-generated R3 (Fig. 3 , data not shown). 
The increase in the accumulation of $R 1$ relative to $R 2$ is not due to alterations in RNA stability

The altered ratio of accumulated $\mathrm{R} 1$ to $\mathrm{R} 2$ that we observed after transfection of mutant p385UTT and pNS2-
2018 plasmids was not the result of altered stability of any of the viral RNAs. Characterization of the persistence of the individual viral RNAs in the presence of the transcription inhibitors actinomycin D (Fig. 5, lanes 2-16) or the adenosine analog 5,6-dichloro-1-ßD-ribofura-
A
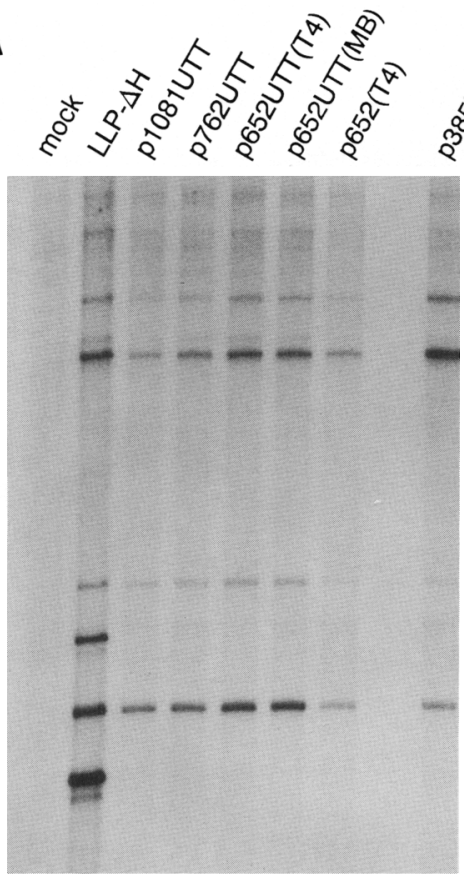

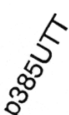

-R1un-

-R1m-

-R1M-

-R3un-

$\mathrm{R} 2 \mathrm{~m}-$

-R3m-

-R2M-

- R3M-

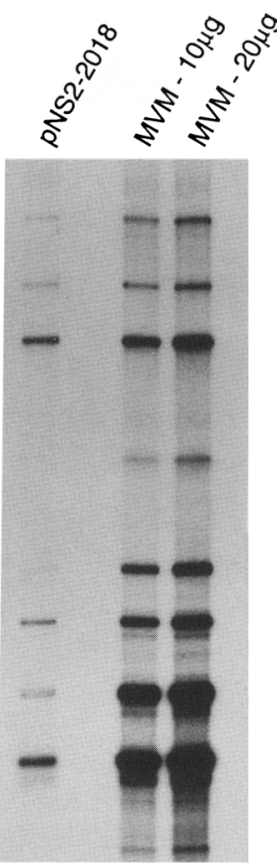

B
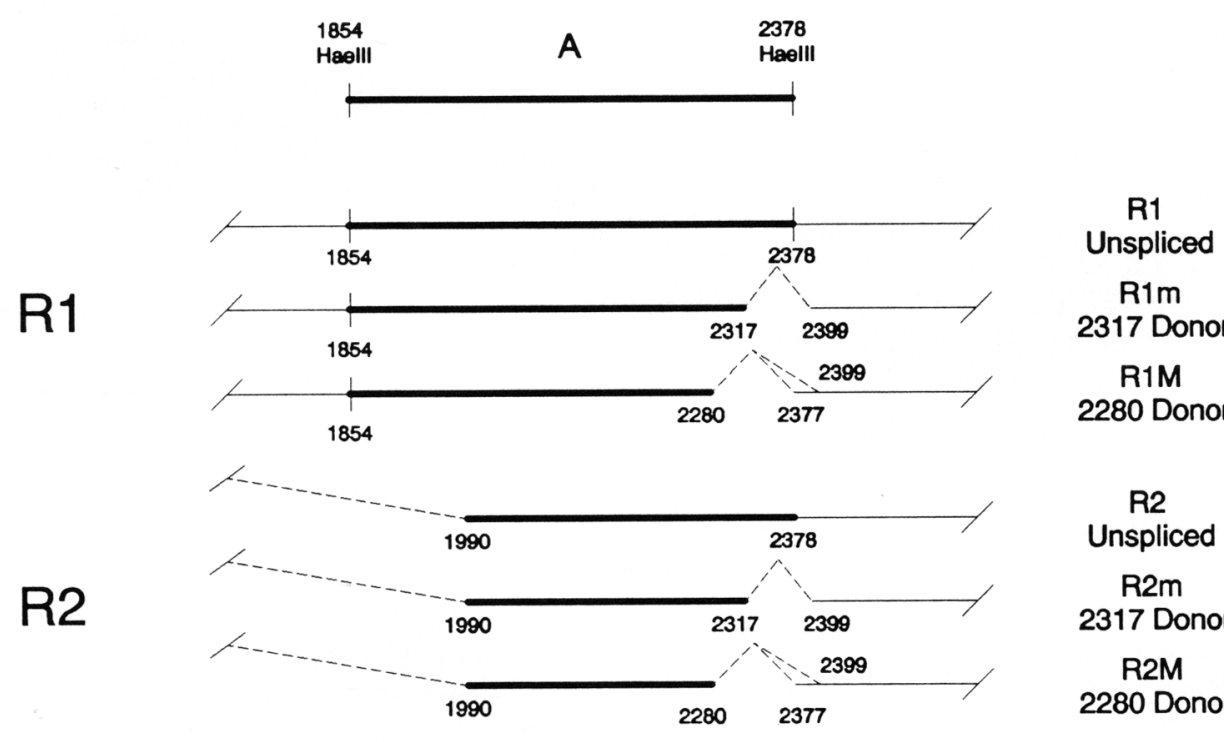

R1 Unspliced

R1m 2317 Donor

R1M 2280 Donor

\section{Protected Size (Nucleotides)}
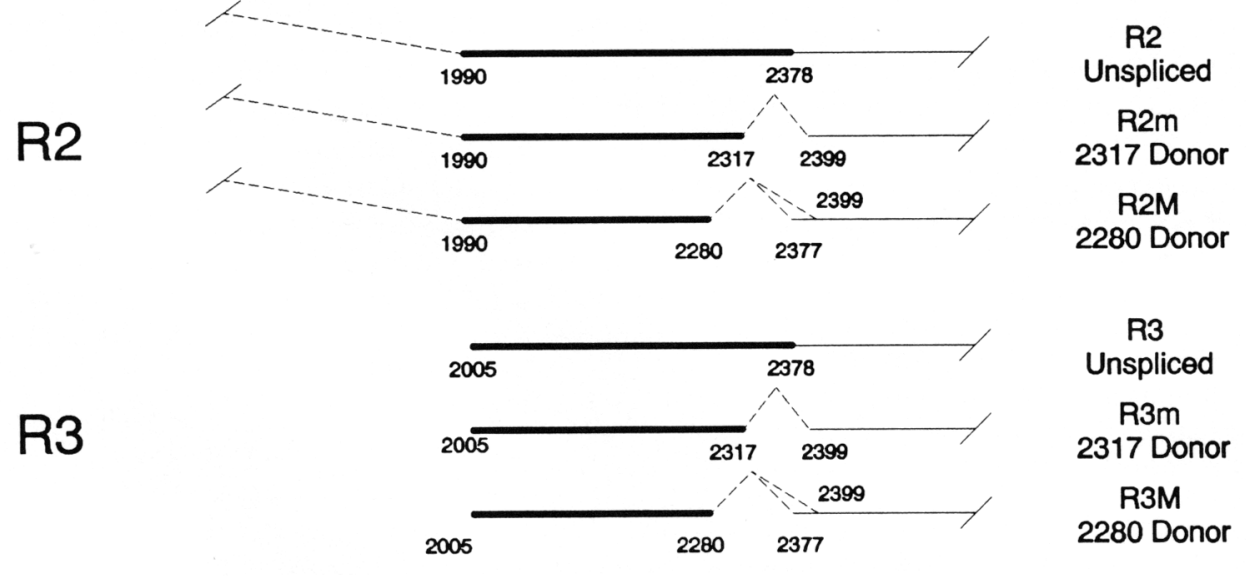

Figure 2. (See facing page for legend.) 
Table 1. Ratios of accumulated $R 1 / R 2$ following transfection of mutants

\begin{tabular}{|c|c|c|}
\hline Construct & Relevant genotype & $\mathrm{R} 1 / \mathrm{R} 2^{\mathrm{a}}$ \\
\hline $\mathrm{pLLP} \Delta \mathrm{H}$ & NS1 $1+\left|/ N_{S} 2\right|+1$ & $0.48 \pm 0.04$ \\
\hline p385UTT & NS1 $(-\mid)$ NS2 $(-)$ & $1.83 \pm 0.44$ \\
\hline p1081UTT & NS $1|-| / N S 2 i+1$ & $0.45 \pm 0.27$ \\
\hline p762UTT & NS1 $(-\mid)$ NS2 $(+)$ & $0.43 \pm 0.23$ \\
\hline p652UTT (T4) & NS $1 i-1 / N S 2 i+1$ & $0.47 \pm 0.19$ \\
\hline p652UTT (MB) & NS $1 i-1 /$ NS2 $i+1$ & $0.50 \pm 0.20$ \\
\hline p652 (T4) & NS $1|-| / N S 2 \mid+1$ & $0.54 \pm 0.32$ \\
\hline pNS2-2018 & NS1 $|+|$ /NS2 $|-|$ & $1.10 \pm 0.19$ \\
\hline
\end{tabular}

${ }^{a}$ The ratios presented are the average of the following number of RNase protection assays using probe $\mathrm{A}$, as described in Materials and methods, and include $95 \%$ confidence limits. pLLP $\Delta \mathrm{H}$, 17; p385UTT, 7; p1081UTT, 5; p 762UTT, 5; p652UTT (T4), 5; p652UTT (MB), 5; p652 (T4), 5; pNS2-2018, 10.

nosylbenzimidazole (DRB) (Fig. 5, lanes 17,18), which have different mechanisms of action, showed no altered stability of RNA for either of the mutants. Both mutants generated RNAs with similar half-lives of $>6 \mathrm{hr}$, similar to that determined previously for wild-type MVM RNAs during infection (Schoborg and Pintel 1991).

\section{An increased ratio of accumulated $R 1$ to $R 2$ is seen in both nuclear and cytoplasmic RNAs}

The availability of NS2-2018 mutant virus permitted efficient characterization of the accumulated ratios of R1 to $\mathrm{R} 2$ in both nuclear and cytoplasmic fractions of infected cells. The accumulated levels of $R 1$ relative to $R 2$ generated during NS2-2018 infection (Fig. 6, lanes 2-4) is significantly increased, compared with wild type (Fig. 6, lanes $6-81$, in both nuclear and cytoplasmic fractions (Fig. 6, cf. lane 2 with lanes 3 and 4 , and lane 6 with lanes 7 and 8; Table 2), although the total accumulated levels of $\mathrm{R} 1$ plus $\mathrm{R} 2$ remain the same, as determined by comparison to P38-generated R3 as an internal control (Table $2)$. This suggests that the altered accumulation of $R 1$ to $\mathrm{R} 2$ is not primarily related to RNA transport of R1 or R2 to the cytoplasm and that $\mathrm{R} 2$ is not specifically degraded in the nucleus. This is also consistent with results demonstrating no decrease in the stability of R2 in total RNA. The amount of nuclear RNA is a significant por- tion of MVM-infected total RNA /Clemens and Pintel 1988; Schoborg and Pintel 1991); therefore, specific degradation of $\mathrm{R} 2$ in the nucleus would also be apparent in total RNA (see Fig. 5).

Because accumulated ratios of R1 to R2 generated during NS2-2018 infection are higher in the cytoplasmic fraction than in the nuclear fraction, we cannot exclude an additional effect on the transport of MVM RNA. In the wild-type infection, however, steady-state, accumulated ratios of $\mathrm{R} 1$ to $\mathrm{R} 2$ are lower in the cytoplasmic fraction than in the nuclear fraction. Taken together, these results are consistent with a model in which the rate of specific RNA transport is proportional to its concentration in the nucleus; therefore, such differences would be correspondingly amplified in cytoplasmic RNA compared with nuclear RNA.

\section{The increased ratio of accumulated $R 1$ to $R 2$ is a consequence of a cis-acting signal in the RNA not the absence of a wild-type viral gene product}

The analysis described up to this point demonstrates that the observed increased ratio of accumulated $R 1$ to R2 was not the result of altered stability or transport of MVM RNA but, rather, the accumulated levels of R1 increased at the expense of $\mathrm{R} 2$. This suggested that the splicing of R1 to R2 was being inhibited. The data also suggested that perhaps the MVM NS2 protein might play a critical role in the regulation of processing of $\mathrm{R} 1$ to $\mathrm{R} 2$. Attempts to reverse the increased accumulated ratio of R1 to R2 generated from p385UTT, however, by complementation with NS2 in trans were unsuccessful. In these experiments, over a broad range of plasmid concentrations, pSVNS1/NS2, a plasmid that expresses the MVM nonstructural genes from the SV40 early promoter /Clemens et al. 1990), showed no effect on the accumulated ratio of $\mathrm{R} 1$ to $\mathrm{R} 2$ generated by the mutant $\mathrm{p} 385 \mathrm{UTT}$ test plasmid (data not shown); even the P38 promoter of that plasmid was stimulated strongly by the nonstructural genes in trans. Attempts to complement p385UTT with constructs expressing an MVM NS2 cDNA /Clemens et al. 1990) were also unsuccessful (data not shown).

These results implied that perhaps the ochre termination signals, artificially introduced into MVM RNA, might act in cis, as has been described previously in

Figure 2. Artificially introduced termination signals interrupting MVM nonstructural genes affect relative accumulated RNA levels. (A) RNase protection analysis of $40 \mu \mathrm{g}$ of total RNA isolated from A9 cells $48 \mathrm{hr}$ post-transfection with $20 \mu \mathrm{g}$ of mutant plasmid DNA per dish is indicated. The final two lanes are RNase protection assays of 10 and $20 \mu \mathrm{g}$ of total RNA taken from MVM-infected A9 cells, serving as a control to assure that protection assays were carried out in probe excess. Locations of mutations are indicated in Fig. $1 \mathrm{~A}$. RNase protection probe A (nucleotides 1854-2378) was used. The identities of the protected bands are diagramed as follows. $(B)$ Unspliced and alternative splicing patterns of the R1, R2, and R3 transcripts are shown, and the corresponding RNase-protected regions, designated in bold, after hybridization to SP-6 generated antisense probe A (MVM nucleotides 1854-2378). The acceptor site for the large R2 splice lies at nucleotide 1990, and the initiation site for the R3 RNAs lies at approximately nucleotide 2005 . Three splicing patterns are used to excise the small intron at map units $44-46$ common to all three transcript classes. The major pattern |found in $\sim 80 \%$ of molecules of all transcript classes) joins nucleotide 2280 to 2377 . The minor pattern (found in $\sim 15 \%$ of molecules of all transcript classes) joins nucleotide 2317 to 2399 . A rare pattern, present in $<5 \%$ of MVM-spliced RNA joins nucleotide 2280 to 2399. M represents protection by those molecules that use the predominant splice donor at nucleotide 2280 ; $\mathrm{m}$ represents protection by those molecules that use the less frequently used donor at nucleotide 2317. 


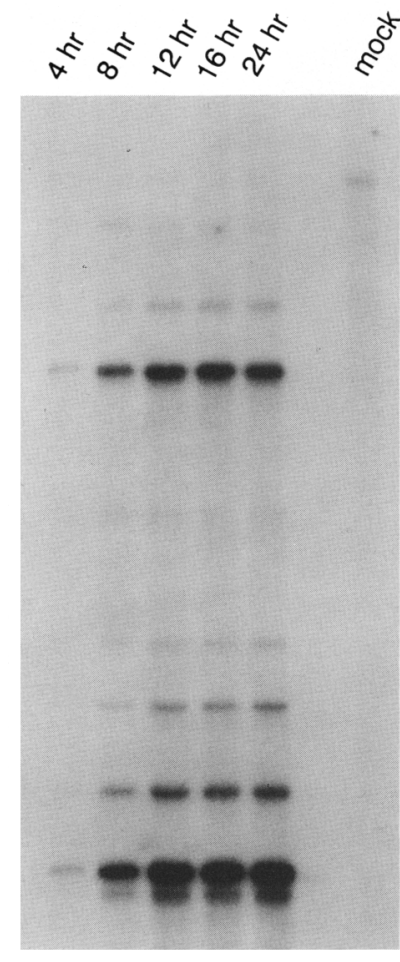

$\begin{array}{lllll}0.9 & 1.1 & 0.7 & 0.8 & 0.9\end{array}$

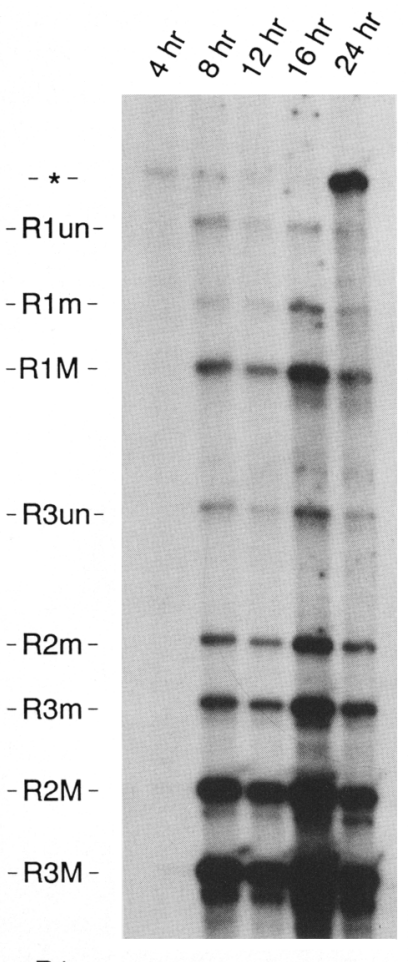

$\begin{array}{lllll}0.4 & 0.3 & 0.2 & 0.2 & 0.3\end{array}$

Figure 3. Mutant NS2-2018 demonstrates increased accumulated levels of $R 1$ relative to $R 2$ throughout infection of murine fibroblasts. RNase protection analysis of total RNA isolated from NS2-2018 (left) and wild-type-infected A9 murine fibroblasts (right). Probe A-2018 (nucleotides 1854-2378) was used to protect $10 \mu \mathrm{g}$ of total RNA isolated from highly synchronized A9 cells infected at m.o.i. 2 with NS2-2018 virus (left). Probe A (nucleotides 1854-2378) was used to protect $10 \mu \mathrm{g}$ of total RNA isolated from highly synchronized A9 cells infected at m.o.i. 1 with wild-type virus (right). RNA was collected at 4, 8, 12, 16, and $24 \mathrm{hr}$ postrelease, as indicated. Mock-infected RNA is protected in the lane indicated. The identities of the protected bands are as described in Fig. 2B. The average relative accumulated $R 1$ versus $R 2$ ratios taken from three separate infections with NS2-2018 and wild-type-infected A9 cells for each time point is shown at the bottom of each corresponding lane.

other systems. Therefore, we constructed mutants p260(T4) and p260UTT(T4) in which the initiating AUG codon for both NS1 and NS2 at nucleotide 260 was removed, thereby preventing their expression. These mutants, which express neither NS1 nor NS2, generated essentially wild-type levels of accumulated Rl relative to R2 (Fig. 7). The absence of functional nonstructural proteins in these mutants was demonstrated by the absence of the P38-generated viral R3 RNA (Fig. 7), which in parallel experiments could be stimulated in trans by pSVNS1/2 (data not shown). These experiments established that neither NS1 nor NS2 participates in the regulation of the accumulated levels of $\mathrm{R} 1$ relative to $\mathrm{R} 2$ and suggested that the ochre termination signals acting

in cis are responsible for inhibition of splicing of $\mathrm{R} 1$ to $\mathrm{R} 2$.

The increased ratio of accumulated $R 1$ relative to $R 2$ requires that the nonsense codon interrupt a previously open reading frame

Because the observed increase in the accumulated ratio of R1 to R2 (described above) was caused by a cis-acting effect, we expected that alteration of the processing of $\mathrm{R} 1$ to R2 might require that the termination signal interrupt a previously open reading frame. To examine this hypothesis and to test whether the interrupted ORF had to

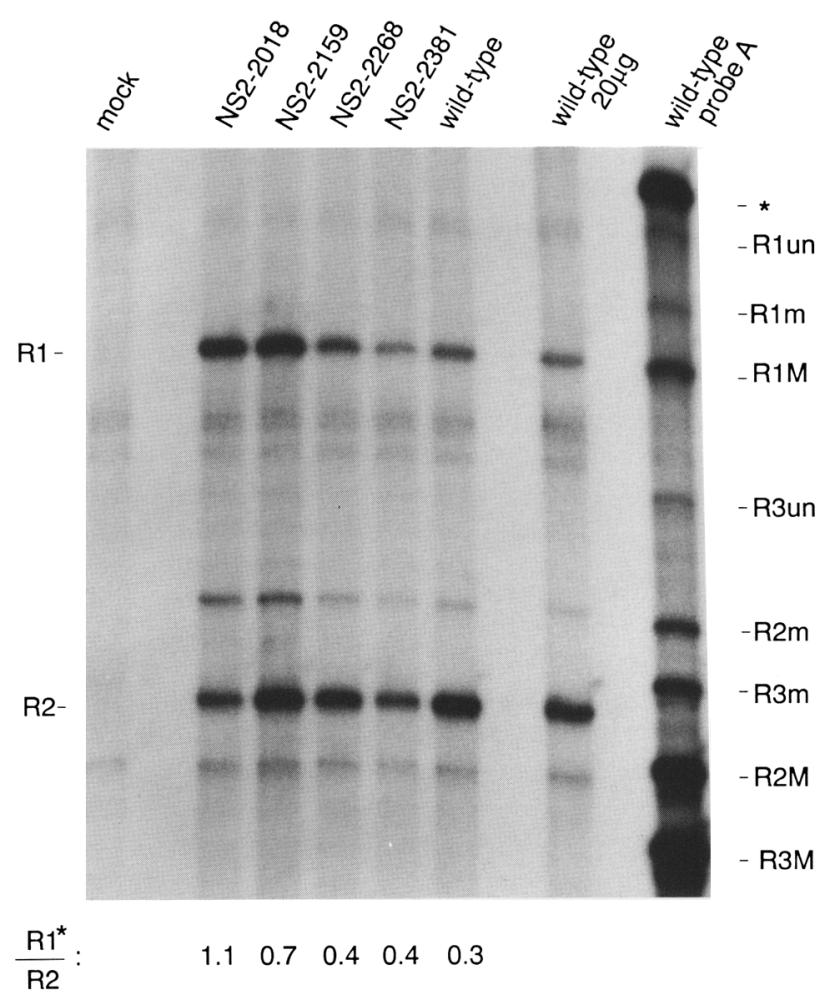

Figure 4. Examination of RNAs generated from NS2 mutants demonstrates that the increased ratios of $R 1$ to $R 2$ are related in a polar fashion to the distance from the initiating AUG. Shown is RNase protection analysis of RNA isolated from murine A9 cells infected with NS2 mutants at a m.o.i. 1. Probe B (nucleotides 146-652) was used to protect $10 \mu \mathrm{g}$ of total RNA taken at $22 \mathrm{hr}$ postinfection with NS2-2018, NS2-2159, NS2-2268, NS22381 , and wild type (lane 6), as indicated. Mock-infected RNA is protected in the first lane, and $20 \mu \mathrm{g}$ of wild-type total RNA is protected in the lane indicated, as a probe excess control. The bands representing protection of probe B by R1 and R2 (451 and 313 nucleotides, respectively; see Fig. 1A) are indicated at left. Wild-type-infected RNA taken at $16 \mathrm{hr}$ postinfection was also protected with probe A (nucleotides 1854-2378), as indicated, and the identities of these protected bands (right) are as described in Fig. 2B. The accumulated ratios of $\mathrm{R} 1$ to $\mathrm{R} 2$ averaged from three different infections are shown for each mutant at the bottom of the corresponding lane. $\left({ }^{*}\right)$ Average of three experiments. 


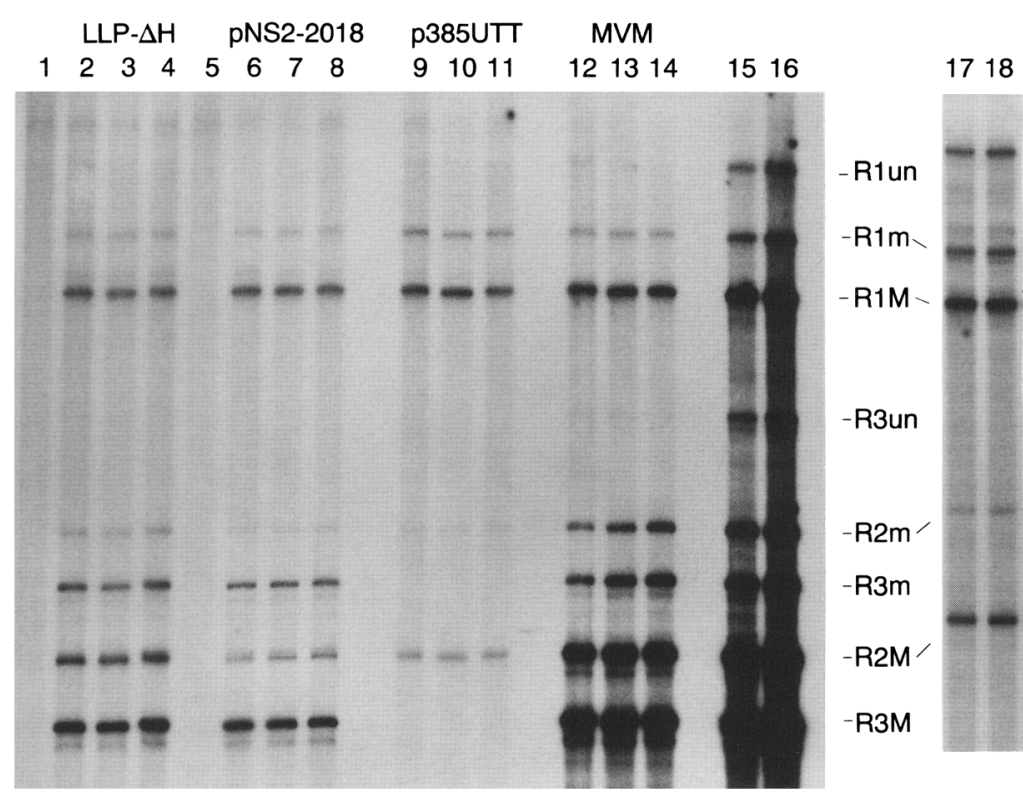

Figure 5. Effects on RNA processing are independent of stability. Shown is RNase protection analysis using probe A (nucleotides 1854-2378), of $40 \mu \mathrm{g}$ of total RNA isolated from A9 cells transfected with pLLP- $\Delta \mathrm{H}$, pNS2-2018, p385UTT, as indicated, mock-transfected /lanes 1,5 ), or $10 \mu \mathrm{g}$ of total RNA from A9 cells infected with MVM at m.o.i. 1 (lanes 12-14). Forty-eight hours after transfection (or $9 \mathrm{hr}$ after infection of highly synchronous cells), cells were treated with $40 \mu \mathrm{g} / \mathrm{ml}$ of actinomycin D and RNA was collected $0.5 \mathrm{hr}$ (lanes 2,6,9,12), $3.5 \mathrm{hr}$ (lanes $3,7,10,13)$, and $6.5 \mathrm{hr}(4,8,11,14)$ later. Alternatively, cells transfected with p385UTT were treated with $40 \mu \mathrm{g} / \mathrm{ml}$ of DRB and collected $0.5 \mathrm{hr}$ (lane 17) or $3.5 \mathrm{hr}$ (lane 18) later. Lanes 15 and 16 are protections with 10 and $20 \mu \mathrm{g}$ of total RNA taken from untreated MVM-infected A9 cells serving as a control to ensure that assays were carried out in probe excess. The identities of the bands are as described in Fig. 2B. (*) Undigested probe. Unspliced R1 and unspliced $\mathrm{R} 3$ are processed to mature forms within the first $0.5 \mathrm{hr}$ after drug addition (Schoborg and Pintel 1991).

be one that could potentially be joined in-frame to the initiating AUG, we constructed and analyzed the phenotype of a set of mutants based on mutant Tb60, which contains a 2-nucleotide insertion at the TaqI site at nucleotide 2073.

The Tb60 insertion shifts the NS2 reading frame in exon 2 of R2 from ORF 2 into ORF 3, which is normally used to encode the carboxyl terminus of NS1 (Fig. 8). The primary amino acid sequence of the NS2 gene product is therefore altered for most of exon 2 without introducing a nonsense codon until nucleotide 2280-beyond the point where nonsense codons inhibit the splicing of R2 (see Fig. 4). After transfection into A9 cells, Tb60 had a ratio of $\mathrm{R} 1$ to $\mathrm{R} 2$ similar to wild type. These results support our conclusion from experiments described above that the NS2 gene product is not required to accumulate normal ratios of $\mathrm{R} 1$ to $\mathrm{R} 2$.

If the artificially introduced cis-acting signal responsible for the increased accumulated ratio of R1 to R2 must interrupt a previously open reading frame and if that reading frame must have the potential to be joined inframe with the initiating AUG after splicing, the following predictions can be made (Fig. 8). The double mutant Tb60-2018, in which the ochre termination signal in ORF 2 at 2018 lies before the frameshift of Tb60, should generate the same increased accumulated ratio of Rl to $\mathrm{R} 2$ as seen in NS2-2018. Tb60-2159, in which the nonsense mutation at nucleotide 2159 has been shifted from the ORF with the potential to join in-frame with the initiating AUG after splicing to the other ORF that does not, should now have a wild-type ratio of R1 to R2 similar to the parent Tb60. If a new termination signal is now introduced into Tb60, immediately after the frameshift into ORF 3, which can become in-frame with the initiating AUG after splicing (Tb60-2087), the accumulated ratios of $\mathrm{R} 1$ to $\mathrm{R} 2$ would again be expected to be increased. The accumulated RNAs generated by these mutants are consistent with these predictions (Fig. 8) and strongly suggest that the mutant phenotype is dependent on the interruption of a previously open reading frame that must have the potential to become in-frame with the initiating AUG after splicing.

For Tb60, which generates a wild-type ratio of accumulated $\mathrm{R} 1$ relative to $\mathrm{R} 2$, the 2-nucleotide insertion at nucleotide 2073 also shifts ORF 3 to ORF 1, bringing a normally unused amber codon at nucleotides 2086-2088 into frame in NS1 (Fig. 9). Although NS1 is terminatedas confirmed by the absence of P38 transcription from this mutant - the accumulated ratios of R1 to R2 remain like wild type, presumably because either the amber codon terminates the NSI ORF too far downstream from the initiating AUG at nucleotide 260 or because nonsense codons that interrupt previously open reading frames in R1 have no effect. Mutant X27, a 4-nucleotide insertion at the XhoI site at nucleotide 2072, shifts ORF 2 to ORF 1, such that the same amber codon at nucleotides 2086-2088 now becomes in-frame in NS2 (Fig. 9). Splicing of R2 also brings the NS2 in-frame amber codon much closer to the initiating AUG at nucleotide 260. In contrast to $\mathrm{Tb} 60, \mathrm{X} 27$ has a greatly increased accumulated R1 to R2 ratio (Fig. 9). This experiment confirms that the position of the in-frame termination signal is of critical importance to the accumulated $\mathrm{R} 1$ to $\mathrm{R} 2$ ratio and demonstrates that interruption of a previously open reading frame by an amber codon can also affect MVM RNA processing in murine cells.

Results with the NS2 and Tb60 sets of mutants and mutant X27 demonstrate that the relative accumulation 


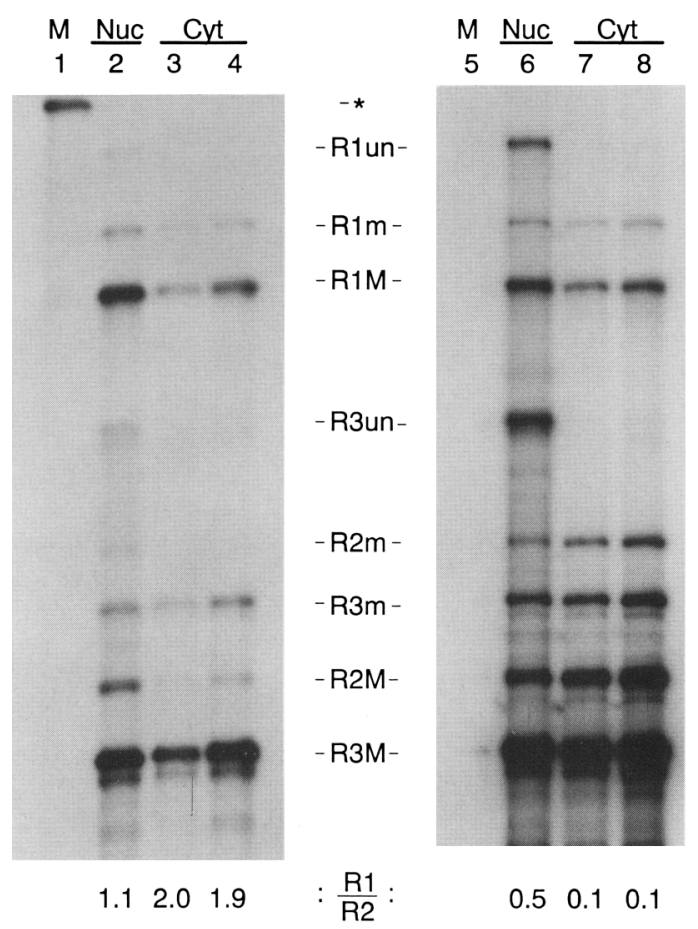

Figure 6. Increased ratios of accumulated R1 relative to $\mathrm{R} 2$ are seen in both nuclear and cytoplasmic RNA fractions. Shown are nuclear and cytoplasmic RNA fractions from NS2-2018 (lanes 1-4) and wild-type (lanes 5-8) infections of A9 murine fibroblasts analyzed by RNase protection analysis. Probe A-2018 (nucleotides 1854-2378) was used to protect $2.5 \mu \mathrm{g}$ of nuclear RNA (lane 2), $10 \mu \mathrm{g}$ of cytoplasmic RNA (lane 3), or $20 \mu \mathrm{g}$ of cytoplasmic RNA (lane 4) (as a probe excess control), from NS22018-infected A9 cells or $20 \mu \mathrm{g}$ of mock-infected RNA (lane 1). Probe A (nucleotides 1854-2378) was used to protect $2.5 \mu \mathrm{g}$ of nuclear RNA (lane 6), $10 \mu \mathrm{g}$ of cytoplasmic RNA (lane 7), or 20 $\mu \mathrm{g}$ of cytoplasmic RNA (lane 8) (as probe excess control) from wild-type-infected A9 cells, or $20 \mu \mathrm{g}$ of mock-infected RNA (lane 5). The identities of the protected bands are as described in Fig. 2B. The average accumulated ratios of $R 1$ versus $R 2$ from nuclear and cytoplasmic fractions in this experiment are shown at the bottom of respective lanes. Nuclear RNA contains unspliced R1 and R3, which is absent from cytoplasmic RNA; however, there is no detectable unspliced R2 [molecules that have lost the large intron between nucleotides 514 and 1989 but not the small intron at map units 44-46) during MVM infection (Schoborg and Pintel 1991). Previous characterization of MVM RNA generated throughout infection has shown that MVM RNA in the nucleus comprises a significant percentage of total MVM RNA, as measured by the abundance of unspliced Rl and R3 (Clemens and Pintel 1988; Schoborg and Pintel 1991). In comparison with numerous other experiments, unspliced $\mathrm{R} 1$ is underrepresented in the nuclear fraction of this sample of NS22018-infected RNA. This was not a reproducible result and does not alter the total increased ratio of R1 to R2 seen for NS2-2018 infections.

of $\mathrm{R} 1$ relative to $\mathrm{R} 2$ can be increased by nonsense codons located in the second exon of R2, $3^{\prime}$ to the large R2 splice, but only when they interrupt ORFs that have the potential of joining in-frame to the initiating AUG after splicing.

\section{Discussion}

The 3.3-kb R2 mRNA of MVM is generated by further splicing of polyadenylated 4.8-kb R1 mRNA /Schoborg 1991; Schoborg and Pintel 1991; R.V. Schoborg, G. Tullis, Q. Zhao, and D. Pintel, unpubl.; R.V. Schoborg, Q. Zhao, and D.J. Pintel, in prep.) (Fig. 1B). Regulation of the splicing of $\mathrm{R} 1$ to $\mathrm{R} 2$ is mediated, at least in part in cis, by the existence of a nonconsensus donor site for the large splice (nucleotides 514-1989) of R2 (Schoborg 1991; Schoborg and Pintel 1991; R.V. Schoborg, G. Tullis, Q. Zhao, and D. Pintel, unpubl.; R.V. Schoborg, Q. Zhao, and D.J. Pintel, in prep.). Throughout wild-type MVM infection, the relative accumulated levels of R1 and R2 are a critical parameter in determining the steady-state levels of NS1 and NS2 (Schoborg and Pintel 1991) and the optimal balance between the essential roles of these proteins in viral replication and cytotoxicity.

Our experiments show that nonsense codons artificially introduced into the nonstructural genes of MVM result in a significantly increased ratio of accumulated viral $R 1$ relative to $R 2$. This increase in accumulated $R 1$ relative to R2 is independent of RNA stability and transport and is mediated by cis-acting nonsense codons rather than by the absence of a functional viral gene product.

Although termination signals that interrupt MVM ORFs significantly increase the accumulated ratio of $\mathrm{R} 1$ relative to R2, the total accumulated levels of R1 plus R2 remain the same. This is shown clearly for mutant NS22018, where the viral P38 products (R3 RNAs) can be compared as an internal control. In NS2-2018 infection or transfection of A9 cells, the accumulated levels of the $\mathrm{P} 4$ products ( $\mathrm{R} 1$ plus $\mathrm{R} 2$ ) relative to $\mathrm{R} 3$ remain the same in both nuclear and cytoplasmic fractions; only the ratio of R1 to R2 has changed (Table 2). This suggests that nonsense codon mutations act in cis to inhibit the splicing of $\mathrm{R} 1$ to $\mathrm{R} 2$, rather than to cause a decrease in R2 stability or affect transport of R1 or R2 out of the nucleus.

Nonsense mutations in the second exon of R2 can inhibit splicing of R1 to R2 but only when they interrupt ORFs that have the potential to be joined in-frame with the initiating AUG after normal splicing. In wild-type virus, there are two ORFs in the second exon of R2. A nonsense mutation at nucleotide 2159 (NS2-2159), which interrupts the ORF that is joined in-frame to the initiating AUG at nucleotide 260, inhibits splicing of R1 to R2. In mutant Tb60-2159, in which a frameshift at nucleotide 2073 shifts the nonsense mutation at nucleotide 2159 into an ORF that can no longer be joined in-frame to the initiating AUG, splicing from $R 1$ to $R 2$ is unaffected. When a nonsense mutation is introduced into the ORF in Tb60, which now can become in-frame with the initiating AUG (Tb60-2087), splicing is again inhibited.

Similar to other observations of this type (Takeshita et al. 1984; Baumann et al. 1985; Baserga and Benz 1988; Urlaub et al. 1989; Cheng et al. 1990), the magnitude of the increased accumulation of $\mathrm{R} 1$ relative to $\mathrm{R} 2$ is re- 
Table 2. Accumulated $R 1-R 2$ and $(R 1+R 2) / R 3$ ratios in total, nuclear and cytoplasmic RNA generated by NS2-2018 and wild-type MVM

\begin{tabular}{llccr}
\hline & & & RNA \\
\cline { 3 - 4 } NS2-2018 & & total & nuclear & cytoplasmic \\
& $\mathrm{R} 1 / \mathrm{R} 2$ & $1.32 \pm(0.25)$ & $1.30 \pm(0.27)$ & $2.03 \pm(0.36)$ \\
wild-type & $(\mathrm{R} 1+\mathrm{R} 2) / \mathrm{R} 3$ & $0.58 \pm(0.14)$ & $0.55 \pm(0.06)$ & $0.46 \pm(0.14)$ \\
& $\mathrm{R} 1 / \mathrm{R} 2$ & $0.48 \pm(0.04)$ & $0.48^{\mathrm{a}}$ & $0.16 \pm(0.02)$ \\
& $(\mathrm{R} 1+\mathrm{R} 2) / \mathrm{R} 3$ & $0.51 \pm(0.09)$ & $0.30 \pm(0.25)$ & $0.55 \pm(0.19)$ \\
\hline
\end{tabular}

The ratios presented are the average of the following number of RNase protection assays using probe A (for wild-type RNA, see Fig. 2B) or probe A-2018 (for NS2-2018 RNA) as described in the text, and includes $95 \%$ confidence limits. Total [NS2-2018 R1/R2, (R1 + $\mathrm{R} 2$ )/R3 and wild-type (R1 + R2)/R3], 8, wild-type (R1/R2), 17; nuclear (NS2-2018 and wild-type), 3; cytoplasmic (NS2-2018 and wild-type|, 8.

${ }^{a}$ Average of two experiments.

lated in a polar fashion to the distance, within an ORF, of the inserted nonsense codons in $\mathrm{R} 2$ from the initiating AUG at nucleotide 260 (Figs. 1A and 10; Table 1). For example, mutant NS2-2159 has a lower ratio of R1 to R2 than NS2-2018, and both of these mutants have a much

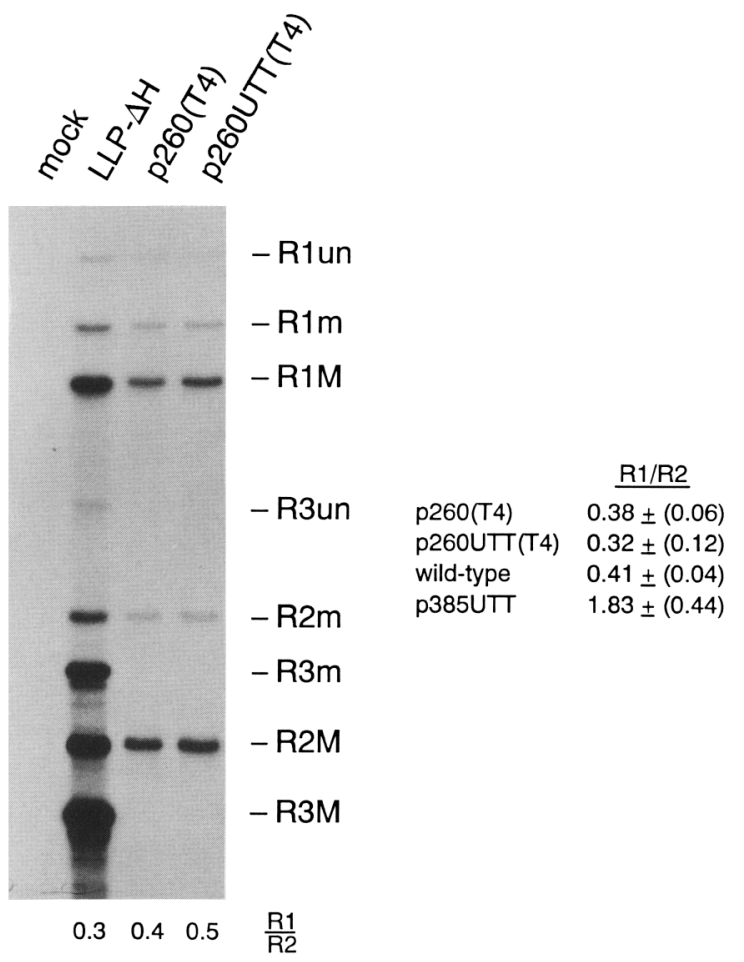

Figure 7. Mutants that do not produce NS1 or NS2 have wildtype ratios of $\mathrm{R} 1$ to $\mathrm{R} 2$. RNase protection assay, using probe $\mathrm{A}$ (nucleotides 1854-2378), of $40 \mu \mathrm{g}$ of total RNA taken $48 \mathrm{hr}$ post-transfection of murine A9 cells with p260(T4), p260UTT(T4), pLLP- $\Delta \mathrm{H}$ (wild type), or mock transfected, as indicated. The identities of the protected bands are as described in Fig. 2B. The relative ratios of $\mathrm{R} 1$ to $\mathrm{R} 2$ for this experiment are shown at the bottom of the lanes. The results from six separate experiments, which include $95 \%$ confidence limits, are shown at right. lower ratio of $\mathrm{R} 1$ to $\mathrm{R} 2$ than $\mathrm{p} 385 \mathrm{UTT}$ (Fig. 10). Because the insertion in p385UTT terminates ORF 3 in both R1 and R2, we cannot exclude the possibility that the increased ratio of R1 to R2 generated by p385UTT is the result of an additional effect in $\mathrm{R} 1$. We have no direct evidence, however, that translation termination signals in $\mathrm{Rl}$ play a role in its RNA processing. Although mutations in p762UTT, p1081UTT, and Tb60 map beyond the distance in R2 that confers an effect on RNA processing, the insertion in p652UTT lies closer to the initiating AUG than the nonsense codon introduced in R2 in NS2-2159, yet has no effect on RNA processing (Fig. $10)$.

Cheng et al. (1990) have presented evidence for the triosephosphate isomerase gene that the distance between a nonsense mutation in exon 6 and the $3^{\prime}$ end of that exon is the critical measure of polarity, rather than the distance to the initiating AUG. If this is the case in MVM, the distance from the nonsense codon and the $5^{\prime}$ end of the small intron at map units 44-46 (Fig. 1A) would be critical in the observed phenotype. The effect of the nonsense codons on MVM RNA processing is similarly polar within $\mathrm{R} 2$ when measured from this landmark. In addition, none of the mutations, including p385UTT, has an effect on the splicing of nascent P4generated RNA into spliced R1. The excision of the small intron, therefore, does not seem to be influenced by premature translation termination.

Premature translation termination has been linked to decreased RNA accumulation in a number of other higher eukaryotic systems. In some of these (Maquat et al. 1981; Graves et al. 1987; Arrigo and Beemon 1988; Peltz et al. 1990), alterations in RNA stability have been clearly implicated. In others, most notably the dihydrofolate reductase (Urlaub et al. 1989) and triosephosphate isomerase (Daar and Maquat 1988; Chang et al. 1990) genes, other aberrations in RNA processing have been identified. In these latter cases, although the exact mechanism for the linkage between translation and RNA processing has not been defined, a model termed "translation/translocation" that links translation with transport to the cytoplasm, is favored. This model, suggested by 

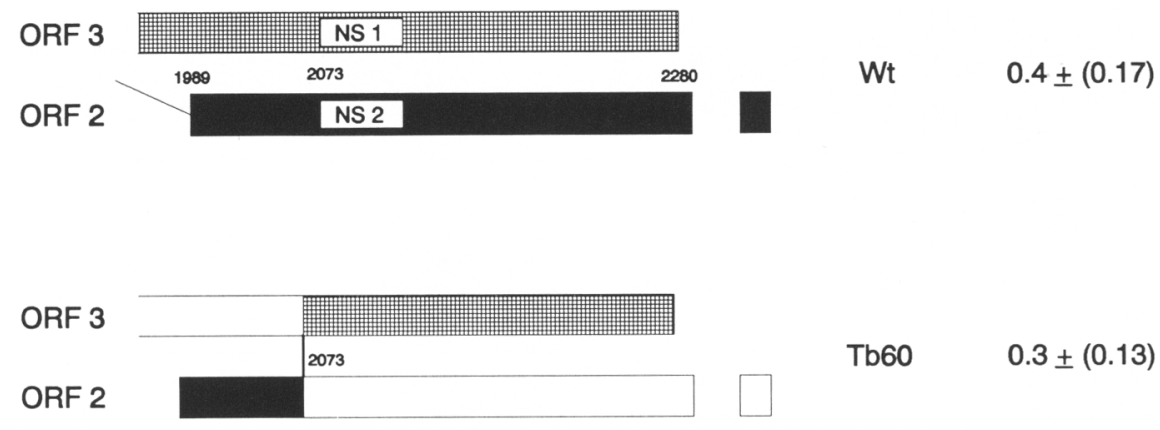

Figure 8. To effect RNA processing, termination signals must interrupt previously open reading frames that have the potential of being joined in-frame to the initiating AUG at nucleotide 260. The map shows the locations of the alterations in the Tb60 set of mutants. Relevant ORFs from the right half of the nonstructural genes (approximately nucleotides 19502400; see Fig. 1A) are shown. The frameshift mutation at nucleotide 2073, which shifts ORF 2 into ORF 3, is indicated by the vertical line. Sites of insertions of ochre termination signals and the reading frames that they interrupt are indicated. The column at right shows the relative accumulated ratio of $R 1$ versus $R 2$ that each mutant generates after transfection into A9 cells and is the average of five experiments, with $95 \%$ confidence limits included. RNase protection analyses were were done as described in Materials and methods using either probe $\mathrm{B}$ or $\mathrm{C}$ (Fig. $1 \mathrm{~A})$.

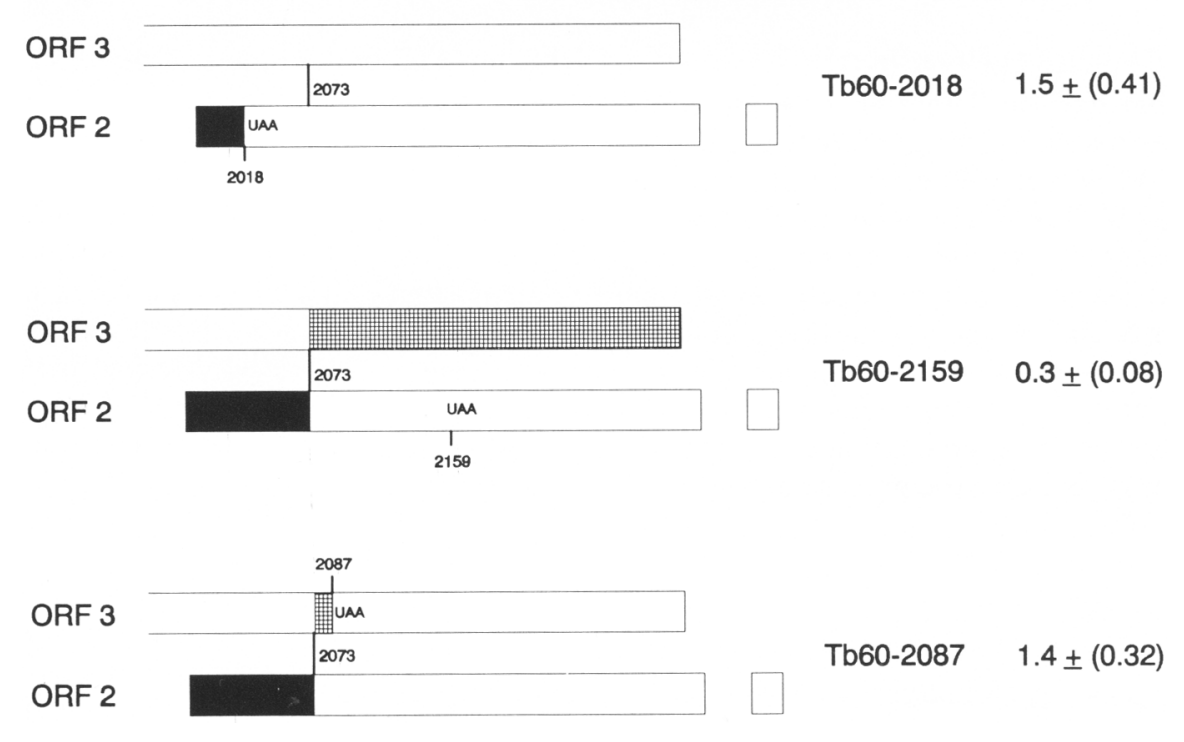

Urlaub et al. (1989), proposes that translation of the $5^{\prime}$ end of an mRNA molecule, on the cytoplasmic side of the nuclear envelope, facilitates transport, whereas splicing of the 3' part of that molecule is still taking place. If translation is terminated prematurely, transport to the cytoplasm is retarded and nuclear splicing is inhibited, presumably leading to increased degradation of that RNA in the nucleus.

Because termination codons that interrupt ORFs in the second exon of $\mathrm{R} 2$ and lie $3^{\prime}$ to the splice that they affect (e.g., mutations in NS2-2018, NS2-2159, and X27) can inhibit the splicing of $\mathrm{R} 1$ to $\mathrm{R} 2$, our results are difficult to reconcile with the translation/translocation model as proposed previously (Urlaub et al. 1989). To conform to this model, ribosomes would need some direct influence on nuclear RNA processing before translation termination. Our results are more consistent with the nuclear exon scanning model also proposed by Urlaub et al. (1989), in which mRNAs are scanned for ORFs in the nucleus before splicing, thus avoiding the use of cryptic splice sites that result in nonproductive products. Such a model might be part of the process of exon definition. Recently, Robberson et al. (1990) have proposed a nuclear exon scanning model in which downstream exons are defined by interactions between splicing factors bound to adjacent splice sites across exons, and perhaps such a mechanism might also include scanning of ORFs. Because the first MVM exon lacks a $5^{\prime}$ splice acceptor site, however, a different recognition point would be required to define this exon. As the effect of the termination signals interrupting an ORF is generally polar with respect to the initiating AUG of NS1 and NS2, such an effect on RNA processing might occur after the spliceosome shortens the distance between the initiating AUG (or the 5' end of the message) and the termination signal by looping out the intervening intron. Scanning of the first exon, however, apparently does not require recognition of the initiating AUG because p260(T4) and p260(T4)UTT, in which the initiating AUG has been removed, splice R1 to R2 normally. Experiments are currently under way to delineate further the role of the initiating AUG codon in this process.

Because nonsense mutations in the second exon of R2 inhibit splicing of $R 1$ to $R 2$ only if they interrupt an ORF 


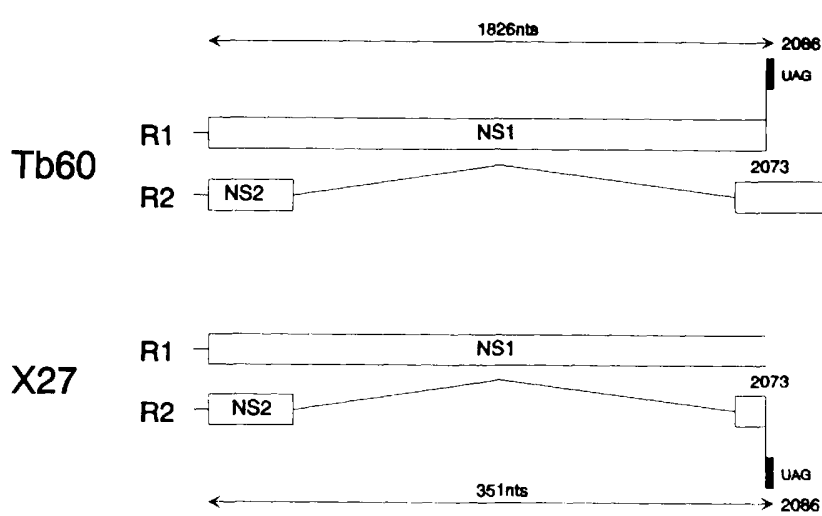

R1:R2 Figure 9. The distance of the amber codon at nucleotide 2086 from the initiating AUG affects its role in RNA processing. The map displays the nonstructural genes of MVM from approximately $0.3 \pm(0.13)$ nucleotides 200 to 2300 . The frameshift in Tb60 shifts the NS1 in R1 from ORF 3 into ORF 1 , where it is terminated by the amber codon at nucleotides 2086-2088, 1826 nucleotides from the initiating AUG at nucleotide 260 . The frameshift $1.5 \pm(0.59)$ in mutant X27 shifts the NS2 in R2 from ORF 2 into ORF 1, where it is terminated by the same amber codon at nucleotides 2086-2088, now 351 nucleotides from the initiating codon at 260 . The column at right shows the relative accumulated ratio of $\mathrm{R} 1$ versus $\mathrm{R} 2$ that each mutant generates after transfection into $\mathrm{A} 9$ cells and is the average of five experiments, including $95 \%$ confidence limits. RNase protection analyses were done as described in Materials and methods using either probe $\mathrm{B}$ or $\mathrm{C}$ (Fig. 1A).

that has the potential to be joined in-frame to the first exon after splicing, there must be a functional cooperation between the exon scanning mechanism and the ability to link ORFs between the normal splice donor and acceptor. As the inhibition of splicing that we detect, however, is not complete, exon scanning is probably only one component of this complex process.

There is growing evidence that nonsense mutations that interrupt a previously open reading frame can effect nuclear RNA-processing events such as splicing and stability. Because the processing pathway for the parvovirus
MVM is relatively simple and well defined, it offers an excellent opportunity to study the relationship between the definition of exons and RNA processing in murine cells.

\section{Materials and methods}

Cells, virus, infections, and transfections

Murine A9 cells were propagated as described previously (Pintel et al. 1983). Wild-type and NS2 mutant virus was titered and propagated, and infections were done as described previously

\section{R1/R2}

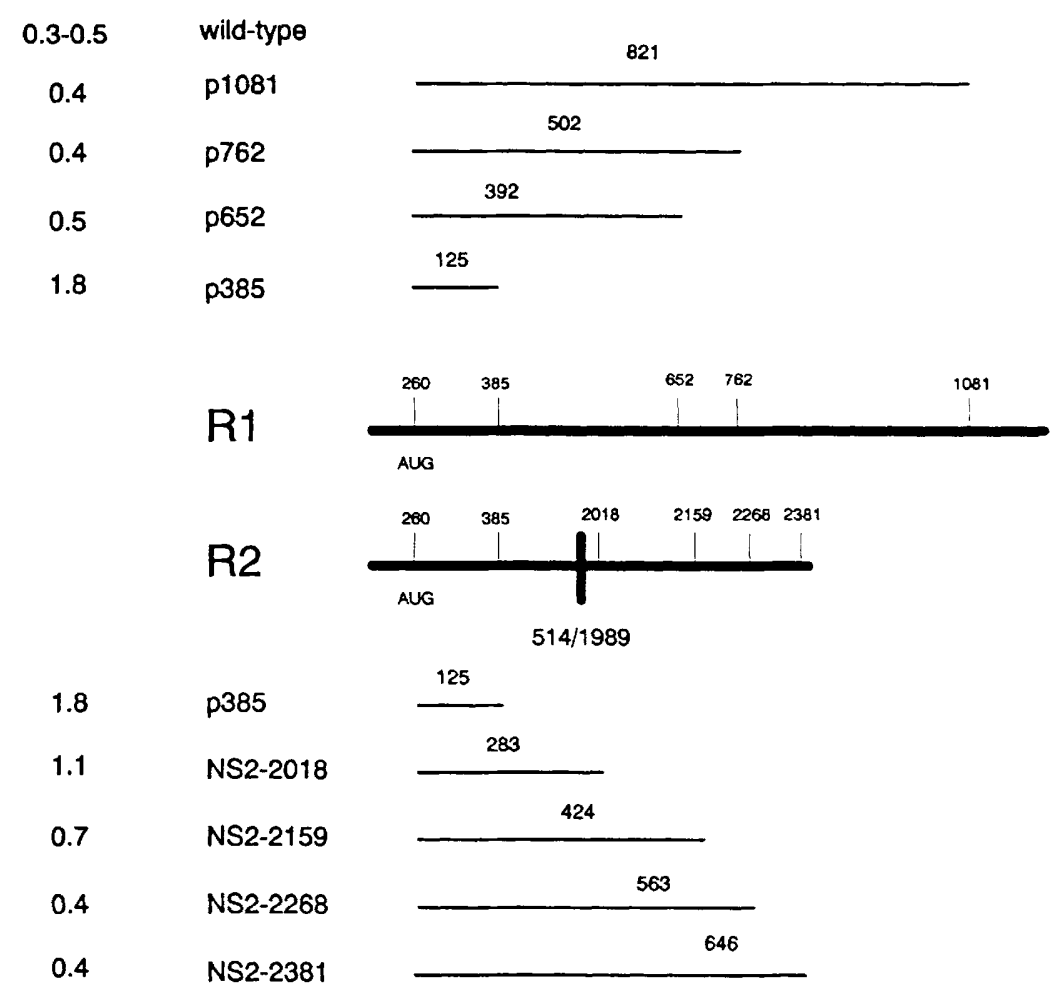

Figure 10. Translation termination signals interrupting ORFs of the nonstructural genes of MVM affect splicing in a polar manner. The map displays the relative distance of artificially introduced termination signals in R1 and R2 from the initiating AUG of NS1 and NS2 at nucleotide 260. The column at left shows the relative accumulated ratio of $R 1$ versus $R 2$ that each mutant generates after transfection or infection of $\mathrm{mu}$ rine A9 cells. All data are summarized from Figs. 2 and 4 and Table 1. 
(Tullis et al. 1988; Naeger et al. 1990). Some infections used highly synchronous cells prepared by a combination isoleucinedeprivation, aphidicolin-blocking protocol as described previously (Clemens and Pintel 1988). Transfections were done using either $\mathrm{CaCl}_{2}$ or DEAE-dextran as described previously (Tullis et al. 1988; Naeger et al. 1990|.

\section{Mutants}

The parent plasmid for all mutants except Tb60 and its derivatives was the original wild-type infectious clone of MVM (Merchlinsky et al. 1983), from which a 1344-nucleotide segment from the capsid gene-coding region was deleted (designated pLLP- $\Delta \mathrm{H}$ ). Extensive characterization of pLLP- $\Delta \mathrm{H}$ has shown that it has transcriptional properties indistinguishable from wild type (data not shown).

Mutants in NS1 and NS2 p385UTT contains a 16-nucleotide palindrome containing ochre TAA signals in all three reading frames [Universal translation termination (UTT) cassette, 5'GCTTAATTAATTAAGC-3' (Pharmacia)] inserted into the EcoRV site at MVM nucleotide 385. To construct p260(T4), pLLP- $\Delta \mathrm{H}$ was linearized at the NcoI site at nucleotide 260 , blunt-ended with T4 DNA polymerase, and closed with ligase. p260UTT(T4) was prepared the same way except the 16-nucleotide termination palindrome described above was added before ligation. The next in-frame AUG codon is 72 amino acids downstream at nucleotide 476 and is in a poor Kozak initiation consensus (Kozak 1986).

Mutants exclusively in NS1 pl081UTT and p762UTT were constructed by inserting the 16-nucleotide termination palindrome into pLLP- $\Delta \mathrm{H}$ at the MstI (nucleotide 1081) and PvuII (nucleotide 762) sites, respectively. For p652(T4) and p652UTT(T4), the parent plasmid was digested with $X \mathrm{cmI}$ (nucleotide 652) blunt-ended with T4 DNA polymerase, and either ligated directly [p652(T4)] or after addition of the 16-nucleotide termination palindrome [p652UTT(T4)]. p652UTT(MB) was constructed as p652UTT(T4), except the molecule was bluntended by mung bean nuclease. The single nucleotide deletion in p652(T4) immediately introduces an ochre termination codon into ORF 3.

Mutants exclusively in NS2 Mutants that affected NS2 exclusively have been described previously (Naeger et al. 1990).

Tb60 and double mutants The Tb60 set of mutants was constructed from the wild-type infectious clone of MVM. Tb60 was constructed by filling in the TaqI site (nucleotide 2073) with the Klenow fragment of DNA polymerase I, which results in a 2-nucleotide insertion, shifting ORF 2 to ORF 3, ORF 3 to ORF 1 (where it terminates with an amber codon at nucleotide 2086), and ORF 1 to ORF 2. Similar insertions were constructed in the NS2-2018 and NS2-2159 mutants to generate Tb60-2018 and NS2-2159 respectively. Mutant Tb60-2087 was constructed by oligonucleotide site-directed mutagenesis using a Tb60 EcoRI fragment from nucleotide 1086-3521 as template, exactly as described previously (Naeger et al. 1990).

Mutant X27 X27 was constructed from the wild-type infectious clone of MVM by filling in the $\mathrm{Xhol}$ site at nucleotide 2072, which generates a 4-nucleotide insertion shifting ORF 3 to ORF 2, ORF 2 to ORF 1 (where it terminates with an amber codon at nucleotide 2086), and ORF 1 to ORF 3.

All mutants were sequenced in the affected areas to ensure the absence of additional mutations.

\section{RNA isolation and characterization}

Total RNA was isolated as described previously (Schoborg and Pintel 1991). Nuclear and cytoplasmic fractionation of infected cellular RNA was done as described (Miller et al. 1989). Nuclear fractions were determined to be $>95 \%$ pure, as monitored by the absence of mature rRNA and the presence of rRNA precursors by ethidium bromide staining after gel electrophoresis (data not shown). RNase protection assays were done, using equal amounts of total, nuclear, or cytoplasmic RNA as indicated, exactly as described (Clemens and Pintel 1988), using an $\left[\alpha_{-}{ }^{32}\right.$ P]UTP-labeled, SP6-generated antisense MVM RNA probe from either MVM nucleotides 1854-2377, 146-652, or 385-652 (diagramed as A, B, and C, respectively, in Fig. 1A), as indicated. Probe A (MVM nucleotides 1854-2378) extends from before the acceptor site of the large R2 splice to within the small intron common to all viral RNAs at map units 44-46 and distinguishes RNA species using either of the alternate small splice donors, designated $M$ for the major splice 2280-2377 and $m$ for the minor 2317-2399 (Fig. 2B; Clemens and Pintel 1988). For analysis of RNA produced after transfection or infection of NS22018 , probe A-2018 was used, which is identical to probe A except that the $G \rightarrow U$ mutation at nucleotide 2018 has been introduced. Probes B (nucleotides 146-652) and C (nucleotides 385-652) distinguish MVM R1 and R2, as indicated in the figures. Northern blot analysis (Pintel et al. 1983) and RNA stability assays using either $40 \mu \mathrm{g} / \mathrm{ml}$ of actinomycin $\mathrm{D}$ or 40 $\mu \mathrm{g} / \mathrm{ml}$ of the adenosine analog DRB (Schoborg and Pintel 1991) were done exactly as described previously. RNase protection assay data were collected on a Betagen B-scanning image analyzer, and molar ratios of MVM RNA were determined by standardization to the number of uridines in each protected fragment. Total R1 and R2 (unspliced as well as spliced) RNA levels were included in the quantitation for each analysis.

\section{Acknowledgments}

L.K.N. and R.V.S. contributed essentially equally to this work; G.E.T. provided additional invaluable discussion. We thank L.B. for excellent technical assistance. This work was supported by U.S. Public Health Service grants RO1 AI 21302 and KO4 AI 00934 to D.J.P. L.K.N. and Q.Z. were partially supported by the University of Missouri-Columbia Molecular Biology Program during a portion of this work.

The publication costs of this article were defrayed in part by payment of page charges. This article must therefore be hereby marked "advertisement" in accordance with 18 USC section 1734 solely to indicate this fact.

\section{References}

Adhya, S. and M. Gottesman. 1978. Control of transcription termination. Annu. Rev. Biochem. 47: 967-996.

Astell, C.R., E.M. Gardiner, and P. Tattersall. 1986. The DNA sequence of the lymphotropic variant of minute virus of mice, MVM(i) and its comparison to that of the fibrotropic prototype strain. J. Virol. 57: 656-669.

Arrigo, S. and K. Beemon. 1988. Regulation of Rous sarcoma virus RNA splicing and stability. Mol. Cell. Biol. 8: 48584867.

Barker, G.F. and K. Beemon. 1991. Nonsense codons within the Rous sarcoma virus gag gene decrease the stability of unspliced viral RNA. Mol. Cell. Biol. 11: 2760-2768.

Baserga, S.J. and E.J. Benz, Jr. 1988. Nonsense mutations in the human $\beta$-globin gene affect mRNA metabolism. Proc. Natl. 
Acad. Sci. 85: 2056-2060

Baumann, B., M.J. Potash, and G. Kohler. 1985. Consequences of frameshift mutations at the immunoglobulin heavy chain locus of the mouse. EMBO /. 4: 351-359.

Berns, K.I. 1990. Parvovirus replication. Microbiol. Rev. 54: 316-329.

Brown, A.J.P. 1989. Messenger RNA stability in yeast. Yeast 5: 239-257.

Cheng, J., M. Fogel-Petrovic, and L.E. Maquat. 1990. Translation to near the distal end of the penultimate exon is required for normal levels of spliced triosephosphate isomerase mRNA. Mol. Cell. Biol. 10: 5215-5225.

Clemens, K.E. and D. Pintel. 1987. Minute virus of mice (MVM) mRNAs predominated polyadenylate at a single site. Virology 160: 511-514.

-1988. The two transcription units of the autonomous parvovirus minute virus of mice are transcribed in a temporal order. J. Virol. 62: 1448-1451.

Clemens, K.E., D.R. Cerutis, L.R. Burger, G.Q. Yang, and D. Pintel. 1990. Cloning of MVM cDNAs and preliminary analysis of individual viral proteins expressed in murine cells. $J$. Virol. 64: 3967-3973.

Cotmore, S.F. and P. Tattersall. 1986. Organization of the nonstructural genes of the autonomous parvovirus MVM. $J$. Virol. 58: 724-732.

- 1987. The autonomously replicating parvoviruses of vertebrates. $A d v$. Virus Res. 33: 91-174.

1990. Alternate splicing in a parvoviral nonstructural gene links a common amino-terminal sequence to downstream domains which confer radically different localization and turnover characteristics. Virology 177: 477-487.

Daar, I.O. and L.E. Maquat. 1988. Premature translational termination mediates triosephosphate isomerase mRNA degradation. Mol. Cell. Biol. 8: 802-813.

Doerig, C., B. Hirt, P. Beard, and J.P. Antonietti. 1988. Minute virus of mice non-structural protein NS-1 is necessary and sufficient for trans-activation of the viral P39 promoter. J. Gen. Virol. 69: 2563-2573.

Graves, R.A., N.B. Pandey, N. Chodchoy, and W.F. Marzloff. 1987. Translation is required for regulation of histone mRNA degradation. Cell 48: 615-626.

Humphries, R.K., T.J. Ley, N.P. Anagnou, A.W. Baur, and A.W. Nienhaus. 1984. $\beta_{\mathrm{o}}$-Thalassemia gene: A premature termination codon causes $\beta$-mRNA deficiency without affecting cytoplasmic $\beta$-mRNA stability. Blood 64: 23-32.

Jongeneel, C.V., R. Sahli, G.K. McMaster, and B. Hirt. 1986. A precise map of splice junctions in the mRNAs of minute virus of mice, an autonomous parvovirus. J. Virol. 59: 564 573.

Kennell, D.E. 1986. The instability of messenger RNA in bacteria. In Maximizing gene expression, (ed. W. Reznikoff and L. Gold), pp. 101-142. Butterworth Publishers, London, UK.

Kozak, M. 1986. Point mutations define a sequence flanking the AUG initiator codon that modulates translation by eucaryotic ribosomes. Cell 44: 283-292.

Labieniec-Pintel, L. and D.J. Pintel. 1986. The minute virus of mice P39 transcription unit can encode both capsid proteins. J. Virol. 57: 1163-1167.

Losson, R. and F. Lacroute. 1979. Interference of nonsense mutations with eukaryotic messenger RNA stability. Proc. Natl. Acad. Sci. 76: 5134-5137.

Maquat, L.E., A.J. Kinniburgh, E.A. Rachmilewitz, and J. Ross. 1981. Unstable $\beta$-globin mRNA in mRNA-deficient $\beta_{o}$ thalassemia. Cell 27: 543-553.

Merchlinsky, M.J., P. Tattersall, J.J. Leary, S.F. Cotmore, E.M. Gardner, and D.C. Ward. 1983. Construction of an infectious molecular clone of the autonomous parvoviruses minute virus of mice. I. Virol. 47: 227-232.

Miller, H., C. Asselin, D. Dufort, J.-Q. Yang, K. Gupta, K.B. Marcu, and A. Nepveu. 1989. A cis-acting element in the promoter region of the murine c-myc gene is necessary for a transcriptional block. Mol. Cell. Biol. 9: 5340-5349.

Morgan, W.R. and D.C. Ward. 1986. Three splicing patterns are used to excise the small intron common to all minute virus of mice RNAs. I. Virol. 60: 1170-1174.

Naeger, L.K., J. Cater, and D.J. Pintel. 1990. The small nonstructural protein (NS2) of the parvovirus minute virus of mice is required for efficient DNA replication and infection virus production in a cell-type-specific manner. J. Virol. 64: 61666175.

Nilsson, G., J.G. Belasco, S.N. Cohen, and A. von Gabain. 1987. Effect of premature termination of translation on mRNA stability depends on the site of ribosome release. Proc. Natl. Acad. Sci. 84: 4890-4894.

Peltz, S.W., G. Brewer, P. Bernstein, P.A. Hart, and J. Ross. 1990. Regulation of mRNA turnover in eukaryotic cells. Crit. Rev. Eukaryotic Gene Expression 1: 99-126.

Pintel, D., D. Dadachanji, C.R. Astell, and D.C. Ward. 1983. The genome of minute virus of mice, an autonomous parvovirus, encodes two overlapping transcription units. Nucleic Acids Res. 11: 1019-1038.

Rhode, S.L. III. 1985. trans-activation of parvovirus p38 promoter by the $76 \mathrm{~K}$ noncapsid protein. $J$. Virol. 55: 886-889.

Robberson, B.L., G.J. Cote, and S.M. Berget. 1990. Exon definition may facilitate splice site selection in RNAs with multiple exons. Mol. Cell. Biol. 10: 84-94.

Schoborg, R.V. 1991. "Accumulation of MVM gene products is differentially regulated by transcription initiation, RNA processing and protein stability." Ph.D. thesis, University of Missouri-Columbia, Columbia, MO.

Schoborg, R.V. and D. Pintel. 1991. Accumulation of MVM gene products is differentially regulated by transcription initiation, RNA processing, and protein stability. Virology 181: 22-34.

Takeshita, K., B.G. Forget, A. Scarpa, and E.B. Benz Jr. 1984. Intranuclear defect in $\beta$-globin mRNA accumulation due to a premature translation termination codon. Blood 84: 1322.

Tullis, G.E., L. Labieniec-Pintel, K.E. Clemens, and D.J. Pintel. 1988. Generation and characterization of a temperature-sensitive mutation in the NS-1 gene of the autonomous parvovirus minute virus of mice. J. Virol. 62: 2736-2744.

Urlaub, G., P.J. Mitchell, C.J. Ciudad, and L.A. Chasin. 1989. Nonsense mutations in the dihydrofolate reductase gene affect RNA processing. Mol. Cell. Biol. 9: 2868-2880. 


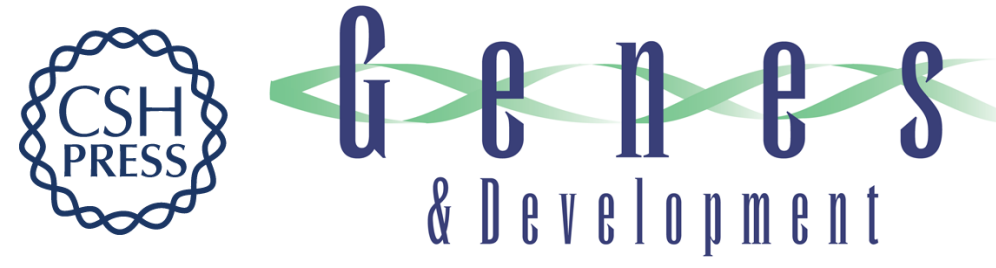

\section{Nonsense mutations inhibit splicing of MVM RNA in cis when they interrupt the reading frame of either exon of the final spliced product.}

L K Naeger, R V Schoborg, Q Zhao, et al.

Genes Dev. 1992, 6:

Access the most recent version at doi:10.1101/gad.6.6.1107

References This article cites 37 articles, 23 of which can be accessed free at: http://genesdev.cshlp.org/content/6/6/1107.full.html\#ref-list-1

License

Email Alerting

Service

Receive free email alerts when new articles cite this article - sign up in the box at the top right corner of the article or click here.

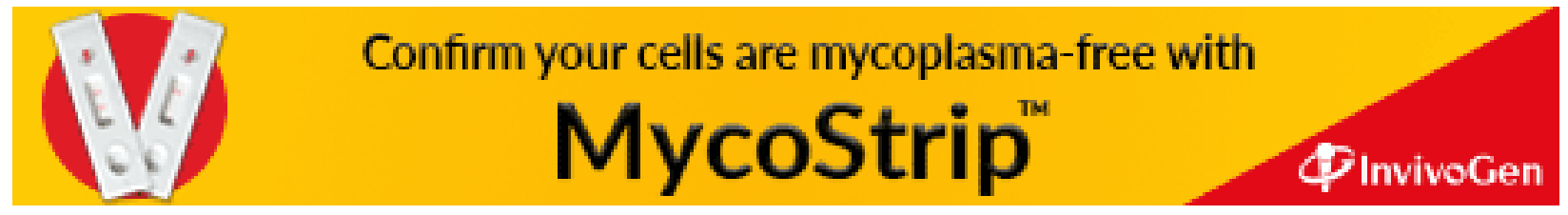

